\title{
Right ventricular reversible perfusion defects
}

To the Editor,

We thank Zhou et al. ${ }^{1}$ for their careful reading of our manuscript ${ }^{2}$ and for pointing out an error in the abstract. We agree that the age and gender were not statistically different between the cases and controls. In fact, no statistical comparison was intended, and we did not report any statistical tests in the body of the manuscript or in Table 1. The reference to statistical comparison in the abstract is an editorial error. As Zhou et al. point out, this does not exert any influence on the results or conclusion of our study. We again thank them for raising our attention to this oversight.
Fadi G Hage, MD, FAHA, FACC, MASNC ${ }^{a, b}$ ${ }^{a}$ Division of Cardiovascular Disease, Department of Medicine, University of Alabama at Birmingham, Lyons Harrison Research Building 306, 1900 University BLVD, Birmingham, AL 35294

${ }^{b}$ Section of Cardiology, Birmingham Veterans Affairs Medical Center, Birmingham, $A L$ e-mail: fadihage@uab.edu

\section{References}

1. Zhou C, Shi J, Liu Y. Letter to the editor for a mistake found in a proof-of-principle study on right ventricular. J Nucl Cardiol. 2019. https://doi.org/10.1007/s12350-019-01608-z.

2. Farag AA, Heo J, Tauxe L, Bhambhvani P, Germano G, Kavanagh $\mathrm{P}$, et al. Detection and quantitation of right ventricular reversible perfusion defects by stress SPECT myocardial perfusion imaging: A proof-of-principle study. J Nucl Cardiol. 2019;26:266-71.

doi:10.1007/s12350-019-01697-w

Publisher's Note Springer Nature remains neutral with regard to jurisdictional claims in published maps and institutional affiliations. 